\title{
Erratum
}

\section{Prediction of settlement of shallow foundations on reinforced soils using neural networks}

A. Soleimanbeigi and N. Hataf

The second right-hand side inset equation in Figure 3 on page 165 was reproduced incorrectly in Geosynthetics International, 2006, 13, No. 4, 161-170. The correct equation is reproduced below.

$$
\mathrm{n}_{\text {out }_{j}}=\frac{1}{1+\mathrm{e}^{-\mathrm{n}_{\text {net }}}}
$$

The publisher regrets this typographical error.

REFERENCE: Soleimanbeigi, A. \& Hataf, N. (2006). Prediction of settlement of shallow foundations on reinforced soils using neural networks. Geosynthetics International, 13, No. 4, $161-170$ 